\title{
College English Teachers' Ecological Niche Research Under the Perspective of MOOCs
}

\author{
Dai Rui \\ English Department, Anhui Sanlian College, Hefei, China
}

\section{Email address:}

1906566671@qq.com

\section{To cite this article:}

Dai Rui. College English Teachers' Ecological Niche Research Under the Perspective of MOOCs. Education Journal. Vol. 4, No. 5, 2015, pp. 308-311. doi: 10.11648/j.edu.20150405.29

\begin{abstract}
MOOCs is a kind of network learning style and has a quite impact on college English teachers, especially for the development of teachers themselves. In the perspective of MOOCs, harmonious ecological niches mean that factors tend to the open type. People can learn the world famous universities' course video after the development of MOOCs. As modern college English teacher, we must change ideas, perceive MOOCs and constantly update the knowledge. We should create new knowledge and improve the level of information. Ecological factors in foreign language teaching system also have the potential to expand its niches, and each factor tries to occupy a larger space for survival and development .The process of the development of the ecological factors is the concrete embodiment of niches expansion. In the vision of MOOCs if teachers most important factors can continuously improve their skills, intelligences and emotional abilities via exchanging energy and then its ecological niches will gradually expansion.
\end{abstract}

Keywords: MOOCs, Ecological Niche, Factors

\section{Introduction}

MOOCs is the new product of education circle. $\mathrm{M}$ refers to Massive, The second letter $\mathrm{O}$ is opening. The third letter $\mathrm{O}$ is online. $\mathrm{C}$ refers to course. That means Massive Open Online Course. By constructing the whole-English study environment English MOOCs Teaching offers English study environment caring online teaching activities to improve the quality of teaching andcreating superior foreign language courses. It contains mini-video, and specified reading literature, participate forum discussion and finish the tasks after class. During the whole process of studying, learners are experiencing the true English, thinking in English, communicating in English, and sufficient revealing the English's instrumental.

From the Ecology, Ecological Niche contains two aspects. One is ecological factorincludingenergy, number of individuals, resource occupancy volume, adaptive capacity, intelligent level, developmental level. This condition is the result from the growth, study, development and interaction of environment. Another aspect is ecological factors' realistic ascendence such as energy substance, converted rate, prolificacy, growth rate, the ability of occupying palingenic environment. The former is regard as ecological niche's condition. The latter is regard as ecological niche's situation. These two aspects reflect specified ecological factors' relative positions and functions at ecosystem. When these two or more factors share their ecological niche's space together, ecological niche overlap will beappearing.If the resources overlap, they have to share resources and cause competitions. During the drastic competitions, if a factor's resources can not satisfy the basic needs, itwill been supplanted or forced toseparated from ecological niche. This is a principle of competitive rejection. The same is Foreign English System as a microcosmic ecosystem refers to a unity that the factors-teachers, students, managers, model teaching, information technology, methods and means ect, and environment interaction.

\section{Literature Review of MOOCs}

MOOCs originated in American colleges and universities. In 2008 the first MOOCs got 2300 registered users. Nowadays, 3 MOOCs platforms have got millions of users. MOOCs for developing speed and wide range are unexpected. Some famous colleges and universities in the US, computer technology and the concept of educating innovation in the aspect of curriculum construction again lead the world 
trend,which arouse people's thinking. At present, edX (online course project), udacity (online university) and course era (course) are called 3 MOOCs platforms (Shang Junjie, 2013:2). Since the US MOOCs for construction has achieved rapid development in 2012, the NEW York times considered 2012 as MOOCs's first year.Since 2013, the People's Daily, GuangMing Daily, China Education Daily such as China proceedings all introduced MOOCs's trend and influence at a marked place. Many top domestic universities have also joined the US large-scale online courses by 3 MOOCs platforms. MOOCs is a new subject of each education worker in colleges and universities. Since 2003 to now, 286 university video courses are open on the Internet. According to the construction goal of "twelfth five-year", there will be 1000 video courses and 5000 resource sharing courses open to the public. Facing the great influence of American MOOCs, many domestic universities have joined MOOC splatforms in 2013. In March Beijing university started the MOOCs for the development work; In May, Tsinghua university and Beijing university and said it signed a contract with edX to expand online education mode. After joining Coursera in July, Shanghai Jiaotong University became the first to join Coursera colleges and universities in mainland China. Sine then, Fudan university and Coursera agreed to provide Coursera network Chinese or English teaching online courses for free.In September, 4 courses of Beijing university are set at the edX, which became the first global shared course launched from mainland China; In October, Tsinghua university launched sharing platform directly and school online (www.Xuetang.com) launched a Chinese MOOCs website which became the first global Chinese MOOCs.

Ecology mainly takes research of the law of the surrounding ecological environment interaction and from the perspective of education. Ecology is to study education problems arising from the environment. Teachers as a key content of the whole education ecological system play an important role and have great influence and teacher's adaptability ability directly affect the technological progress. Information technology represented by computer technology is penetrated into all aspects of society and its effect on education reform also caused society's attention and thinking (Mei Deming, 2014). When it refers to education, people are always putting emphasis on the basis of information technology environment. However, at present, data changes day after day but its precipitation in education does not reach people's original expectation (Chen Jianlin, 2014). Western second language scholar Johnson pointed out that: as his profession is between linguistics, Pedagogy, Language and many other disciplines such as psychology, sociology,anthropology and its teaching practice is also between the two cultures, so the status of the the profession is a verge "postmodern career" (Johnson, 1999). Indeed, for Chinese college English teachers, this marginalization is more obvious: compared with other disciplines, it is considered that this discipline does not need high academic level and student generally neglect and college English credits are under compression constantly and teachers of English to itself gradually belittle or ignore the subject causing lack of research results and weakness of research ability. These problems make college English teachers have been struggling.

\section{Analysis on the Change of Niche in College English Teaching System for MOOCs}

Therefore in the original relative balanced foreign language teaching system MOOCs as "heterogeneity" intrudes away from the teacher factor of niche, the niche overlapping and competition and repulsion between factors and other factors lead to changes between factors relationship and teachers factor inner internal state and potential changes, resulting in foreign language teaching system, the phenomenon of imbalance. From beginning to now, enthusiasm tends to be more rational steady development. Technical equipment idle, teachers in the awkward position and integration of the derivative and many other problems attracted researchers' attention. These imbalances specifically displays in.

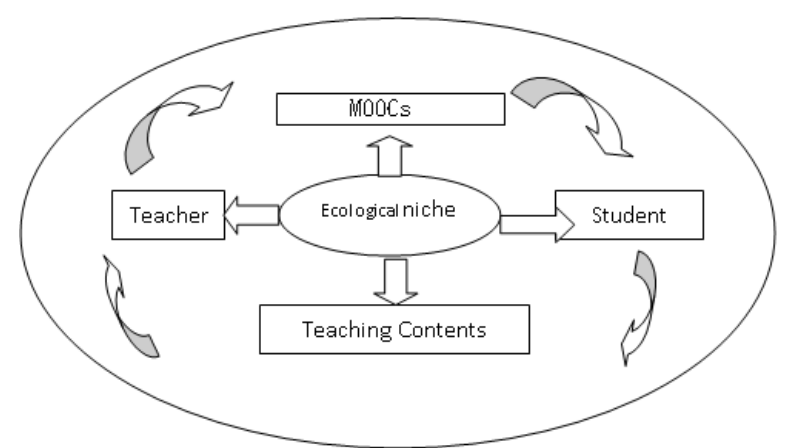

Figure 1. The structure and relationship of teaching ecosystem influced by MOOCs.

\subsection{The Change of the Relationship with Students}

MOOCs let learners have abundant resources and more authentic language environment and they are all free. Students no longer rely on teachers for learning resources, which makes the students gradually away from the control of the teacher and teachers' status is changing quietly with the reducing control of resources. There is no doubt that MOOCS puts forward an unprecedented challenge to teachers, which will promote education resources to the differentiation of combination and evolution. In MOOCS, the level of the teachers is no longer up to school but is decided by students. Teachers level has become the important indicator in choosing teachers. This could make popular teachers abandoned and nobody booming and also it is likely to make the strong stronger, the weak weaker. Therefore, college English teachers will be subject to various constraints even facing survival crisis and become a teaching assistant in the same line if they are less of ability and capacity.

\subsection{The Change of Relations with Teaching Materials}

In MOOCs the majority of teaching materials are designed 
by teachers themselves. Teachers can create a suitable teaching material that can meet student's need. The presentation style of material content has made a breakthrough that the limitations of the simple print media from a single paper to audio and video products, electronic products, video teaching and other forms. The core of teaching style is teaching content with different ways of writing from aspects of listening, speaking, reading and writing to present to teachers and students. With repetition, emphasis, cross and complementary, by mutual cooperation, forming a three-dimensional, a whole way of teaching, students can use teaching materials much more flexiblely and their interests can be stimulated in learning at the same time. The theory and technology requirements for college English teachers is so high that many teachers are under pressure and dose not adapt, so teachers have feeling of resistance.

\subsection{The Change in College English Teaching}

In MOOCs, the teacher's image has also been virtualized and state of matter. Teachers are more hidden behind the scenes. Teaching is through creation of teaching situation, design of courseware and teaching activities, which greatly drops the teacher's image and presence manner. MOOCS has also made a breakthrough in traditional management mode in a certain school that teachers belong to. This mode is beyond region and become more "free". What's more, sharing popular teachers could come true.

\section{Challenges for College English Teachers on the Tide of MOOCs}

Facing the rapid impact of MOOCs and the quick response of domestic colleges and universities, the new reform caused by the internet technology is called a new education revolution initiated by MOOCs. Some people question the revolutionary nature of MOOCs and they think this is not the subversive education innovation. Nor does it change the status and function of school education. Compared with the traditional classroom teaching mode, MOOCs has its distinctive advantages in the aspects of Teaching Ideas ,Teaching Contents ,Teaching Methods and Teaching Efficiency. It's beneficial to improve the level of China's modern education with a positive attitude when facing the challenges of MOOCs.

To cope with the present college English Teaching, some experts believe that the first is to actively involved in the construction of MOOCs. The second is to seriously consider the application of MOOC splatform. The third is to explore the new teaching mode based on MOOCs. (Xiao dong Lee; 2014) For college and universities teachers MOOCs is not only an alarm bell but also the driving force to promote teachers involving in teaching reform as soon as possible.

College English curriculum accounts for high credits of single course in our colleges and universities, and it has been the experimental field of teaching reform. 2007 English Curriculum Requirements (Requirements hereafter) asked colleges and universities should remold the existing unitary teacher-centered pattern of language teaching by introducing computer- and classroom- based teaching models. It aims to stimulate students' learning efficiency through the participation of various senses according to the characteristics of the English language and the multi mode presentation. The Ministry of Education has set up a special project of College English Teaching Reforms, which lead to the implementation of computer and classroom-based college language teaching models and comprehensively promotes the integration of information technology and College English Curriculum. 2012 is known as the first year of the international MOOCs after the rapid rise of the international MOOCs.

\section{Conclusion}

The world's top universities masters' courses open to the learners around the world free of charge. Many universities have put the school curricula on the Internet therefore global learners are free to learn the superior courses of the top universities. These courses cover various fields of Natural Science and Humanities and Social Sciences.2013 is known as the first year of China MOOCs. Chinese colleges and universities joined' the international MOOCs campaign to start building their own MOOCs. Along with the popularization of MOOCs, the college English teaching faces news challenges.

On the one hand, a large number of international noon language MOOCs (English as teaching language) is gradually on line. These courses are equivalent to the whole English major courses offered by some universities in China. On the other hand, British Culture Department announced that they will cooperate with Future Learn to help people improve their English through the construction of large-scale English language MOOCs. These courses (English learning MOOCs) are based on the British culture that offers global students' and teacher's support and assessment experience for many years, and the first course will open to the world in 2014. The new English language MOOCs will enable global learners to receive higher education in English and communicate in English more effectively.

\section{Acknowledgements}

The paper is one of the results of Humanities and Social Science Imporant Project in Anhui Province; Code: SK2015A639 and one of the results of Anhui Province Quality; Code: $2013 z y 086$.

\section{References}

[1] British Council.Platform provided for the British Council"s first ever MOOCs.http://www.britishcouncil.org/organisation/press/platfo rm-provided-british-council"s-firstever-MOOCs. 2013. 
[2] Chambers, A. Popularis ing corpus consu ltation by language learners and teachers[A]. In $\mathrm{H}$ idalgo, E., Q uereda, L. and Santana, J.( eds.). C orpora in the Fore ign Languag e C la ssroom [C]. Am sterdam: R odop, i 2007: 3-16.

[3] Fini, Antonio. The technological dimension of a massive open online course:the case of the CCK08 course tools. International Review of Research in Open and Distance Learning. 2009.

[4] $\mathrm{H}$ ad ley, G. A $\mathrm{n}$ in trodu ct ion to data- driven learn ing [J]. RELC journal, 2002, 33(2): 99-124.

[5] Jeffrey R. Young. Beyond the MOOC Hype: A Guide to Higher Education"s High-Tech Disruption. 2013.

[6] Jeffrey R. Young. Beyond the MOOC Hype: A Guide to Higher Education"s High-Tech Disruption. 2013.
[7] $\mathrm{N}$ orton, B. Iden tity and Language Learning: $\mathrm{G}$ ender, $\mathrm{E}$ thn icity and Educational Chang e[M]. H arlow: Pearson E du cat ion, 2000

[8] Robert J. Blake. New Trends in Using Technology in the Language Curriculum[J]. Annual Review of Applied Linguistics, 2007(27).

[9] S cott, M. \& T ribble, C. T ex tual Pa tterns: K ey W ords and Corpu sAnalysis in Languag e Education [M]. Am sterdam: John Ben jam ins, 2006.

[10] Sasha A. Barab \& Kurt. Squire. Design-based Research: Putting a Stake in the Ground[J]. Journal of the Learning Sciences, 2004, 13(1). 